\title{
Semiotic Analysis of the Textbooks for Young Learners
}

\author{
Anja Sovič ${ }^{1}$, Vlasta Hus ${ }^{2}$ \\ ${ }^{1}$ High School II of Maribor, Maribor, Slovenia \\ ${ }^{2}$ Faculty of Education, University of Maribor, Maribor, Slovenia \\ Email: vlasta.hus@um.si
}

Received 2 March 2016; accepted 17 April 2016; published 20 April 2016

Copyright (C) 2016 by authors and Scientific Research Publishing Inc.

This work is licensed under the Creative Commons Attribution International License (CC BY).

http://creativecommons.org/licenses/by/4.0/

(c) (i) Open Access

\begin{abstract}
Illustration is very important media. It is the media from which children learn especially when they are 5 to 6 years old. If they don't know the meaning of illustration, they find it senseless. Illustration as any material which is used in education, should follow and support child's cognitive development. Semiotics despite its unfamiliarity is very important part of child's cognitive development. Different symbols are learned at different stages and there are a lot of symbols in textbook's illustration. The semiotic analysis of three textbooks for young learners (Playway to English 1, Magic Adventure 2, Cookie and Friends) showed that these textbooks need some corrections according to child's cognitive development and their visual perception. The textbook's illustrations all include "motion devices" and what is ever more the same symbols represent different meanings.
\end{abstract}

\section{Keywords}

Textbook's Illustration, Young Learners, Semiotic Analysis, Visual Perception, Cognitive Development

\section{Introduction}

Textbooks are one of the main school gadgets so it is very important that they are adjusted to children's cognitive development at specific age. There are many aspects on which a textbook can be evaluated. Semiotics in illustration are very specific element especially because they have great influence on children's visual perception. Children's visual perceptual ability differs from that of adults and also from teenagers because of their conceptual development. Markman claims that children have completely different way of categorizing objects from adults (Yu, 2007). Categorization is developed under different factors. One of the main factor is culture. The 
ethic background and age are found significant factors in visual perception (Turkcan, 2013).

"Semiotics is a science about symbols" (Semiotics, 2013) and also means capability of reading symbols. In illustrations we can find a lot of symbols and we just don't realize that they are symbols, because we interpret them automatically. The human being regardless of age has a need for symbolic expression and also even greater need to decode the symbols (Šuštaršič, 2004).

One of the fields transmitting the codes as a system of indicators is art. In semiotic analysis, text, numbers and images are treated as signs (Šuštaršič, 2004). Children "read" art, illustration through symbols. These symbols can be easily seen in children's drawings. Scientists process children's drawings as a indicator of mental development and as a way of expressing his or her complex inner world which the child tries to organize on his or her own (Karlavaris, 1984).

It is fascinating when you realize that semiotic aspects are developed according to the child's age. Viewing images and arriving at interpretations help to train children's cognitive skills as well as creative experience, such as using information (Yu, 2007).

There is a systematic scheme to how symbols are developed. We will focus on 5 - 6 year age group. Children at this age draw notions as parts of action which can be easily connected to the notion. They draw extremely a lot segments which are connected with a notion they want to present. As children get older number of segments decreases and the notion is much more in front. What children draw, which symbols do they use that shows us not only how they think, but also how will they identify illustration (Clyde, 2003).

It can be concluded that best illustrations for children age 5 - 6 are ones that show part of the story, some action which is surrounded by many other figures. A 5 - 6 year old child is not capable of recognizing only one symbol, which is learned through years. The age when a child is capable of recognizing learned, coded symbols is around ten and it reaches peak at age 12 years. We also must take in notice that child's art expressing is a little behind with a child's perception of art expression (Karlavaris, 1984). With another words a child will recognize symbols but she/he won't be able to draw them.

To recognize symbols does not only mean to encourage recognizing process but leads to higher psychical process. These higher psychical processes with connection to letters encourage and lead towards abstract thinking (Karlavaris, 1984).

In many ways, children prove that they group things together not because they are similar but because they achieve function. What is also important is that most children find joy in identifying objects, explaining concepts and retelling stories (Yu, 2007).

Pictures are so real for children that they are carriers of a universal message. Pictures, both moving and still images, contain "cues" which must be interpreted by the viewer. If a person is familiar with picture cues, he or she can accept this quickly without thinking about it. The way to interpret the picture cues derive from one's personal status, personal feelings or personal associations (Yu, 2007).

On the other hand decoding symbols is present also with blind people. Symbols are learned. By age 11 children are capable of decoding symbols in their environment (Karlavaris, 1984). When we think about the way we learn symbols, we first think of sight. However, that is not completely true. We typically think of sight as the perceptual system by which shapes and surfaces speak to the mind. Psychologist John Kennedy proved that this is not completely true. When we see something, we know more or less how it feels to touch. Even so, touch and sight are two different senses, but they work together in some way. It is important to realize this and also to know that children learn to decode symbols not only with the help of sight.

Kennedy found that blind people draw lines that represent movement (Kennedy, 2009).

On the other hand, sighted people are familiar with the use of lines for describing motion from 19th century when Wilhelm Busch used them in cartoons (Kennedy, 2009). What is more, blind people understand visual metaphors (symbols) as well. Blind people interpret abstract shapes as sighted people do (Kennedy, 2009).

Every day we are surrounded by pictures, illustrations that indicate implied motion. These pictures with implied motion harness our good perception of motion to capture the viewer's entire attention. Viewers don't realize this because everything is a subconscious process (Bregant, 2013). Motion perception develops in early infancy, and Kaufmann even confirmed that sensitivity to very rapid motion seems to be at a level comparable to that of adults soon after birth. The reasons for this early visual perception can be found in psychology and anthropology (Kaufman, 1995). Two of these explanations deserve attention in this context.

Anthropology says that human motion perception is developed very early because it is a life depending ability. Humans were hunters, so we had to notice first what was moving. Our brains developed the ability to automati- 
cally concentrate first on what is moving and only then on everything else. We have preserved this ability till today (Kompare, Stražišar, \& Vec, 2001).

Psychology claims that motion is easier to recognize because it includes motion patterns that act as an additional cue to identity. Kourtzi, psychologist, (2002) proved that we have two mechanisms for representing of moving and static objects. Not only do we have different mechanisms for representation, but our brain is more or less activated in observing moving or static objects. When a person sees a moving object temporal cortex in his brain is completely activated and less when he sees a static one. One might argue that it is one thing to see motion in reality and another to see it in an illustration where nothing is actually moving. Scientists Kanwisher and Kourtzi (2000) have proven that illustrations and photographs that have motion implied activate more human motion areas than those illustrations without implied motion (Kourtzi, 2000, 2002). Looking at a visual depiction of motion thus has some of the same effect on our brains as observing motion in the real world. To conclude illustration with implied motion are more noticeable and cause more activation of motion areas in the human brain. Table text styles are provided. The formatter will need to create these components, incorporating the applicable criteria that follow.

\section{Methodology}

Research sample.

The research sample consisted three main publishers of the English textbooks for young learners (age 6). These textbooks were: Playway to English 1 (Cambridge), Cookie and Friends (Oxford: University Press) and Magic adventure 2 (Rokus Klett).

\section{Maintaining the Integrity of the Specifications}

The template is used to format your paper and style the text. All margins, column widths, line spaces, and text fonts are prescribed; please do not alter them. You may note peculiarities. For example, the head margin in this template measures proportionately more than is customary. This measurement and others are deliberate, using specifications that anticipate your paper as one part of the entire journals, and not as an independent document. Please do not revise any of the current designations.

\section{Results}

Before you begin to format your paper, first write and save the content as a separate text file. Keep your text and graphic files separate until after the text has been formatted and styled. Do not use hard tabs, and limit use of hard returns to only one return at the end of a paragraph. Do not add any kind of pagination anywhere in the paper. Do not number text heads-the template will do that for you.

Finally, complete content and organizational editing before formatting. Please take note of the following items when proofreading spelling and grammar:

\subsection{Semiotic Analysis of the Textbook Cookie and Friends}

Many symbols need explanation for children. With reference to Figure 1, we will explain where problems can occur for children in decoding symbols.

In the illustration 1, the two main characters, the blue ball and a little spider are surrounded by white lines. These white lines describe motion, and this graphic technique is called the "motion device". So the ball, the little spider and the main characters are moving. There are 44 illustrations in Cookie and Friends. In 61\% of these illustrations, movement is presented, so only $43 \%$ of illustrations show subjects or objects that are not in motion. Motion is usually indicated by white lines around the moving subject. Children could interpret these lines as strings in the air, or as clouds etc. The ball also comprises 2 circular shapes (2 balls). One is dark blue and the other is much smaller and white (you can see it at the right edge of the ball). A child at the age of 6 would probably interpret this mini-ball as a decoration or maybe as another ball. We know, however, that illustrator is trying to show us that the Sun was shining and that this ball shows a reflection. Children can decode shadows easily, because they can see these in every day life situations, if the sun is shining. That isn't sufficient reason for not explaining to children that there is also a shadow in the illustration. According to the national curriculum for kindergarten, children learn about shadow at the age of five. 


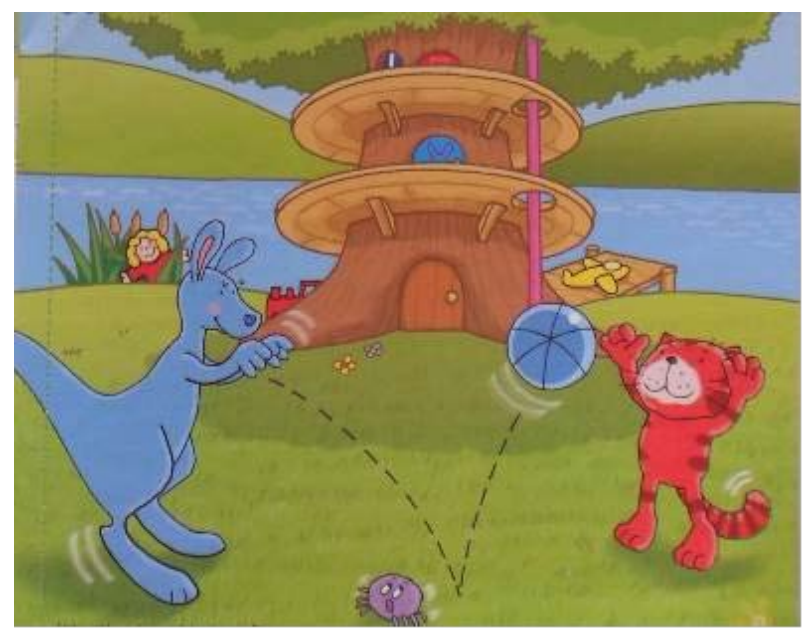

Figure 1. Illustration. Source: Harper, 2006.

In addition, this kind of illustration depicts a different world from the one in which children live. It is presented almost as a wonder world, where everything is in order and where all that they do is play. The main characters have no obligations and no limits. They are shown in some pictures as if they were flying. In Cookie and Friends, 24 illustrations depict an environment with no floor and no boundaries. The main characters and objects appear to float in this indefinite space. These illustration comprise around 55\% of all the illustrations.

Also a symbol for singing (musical note) can be found several times in textbook. In textbook Cookie and Friends we can also find long sentences written and also numbers. Not only are sentences inappropriate for sixyear olds, but so is the font in which they are written. The sentences are written in lowercase, not in capitals, as children are taught in other subjects.

\subsection{Semiotic Analysis of the Textbook Magic Adventure 2}

In the Magic Adventure 2 textbook there are many symbols which could cause problems for the children decoding them. These are examples of illustrations that could potentially cause problems for the children decoding them.

Figure 2, on the right, shows something like flying or at least movement into the air. The lines show movement, but we have to know that the shape of these lines could also describe a tornado or a hurricane. What is more, we can see shapes like clouds which are much smaller than the girl and boy. Movement in illustration is common. In Magic Adventure 2 more than half the illustrations (53\%) contain a 'motion device' or feature some movement. Only $47 \%$ of illustrations contain static characters or objects.

On Figure 3 we can see some angular lines around the main characters. What do these lines represent? Movement, shine or dropping? We cannot say for sure, but we can predict that it would be difficult for young children to understand. Particularly in the absence of verbal text.

It could represent a space without any limits, boundaries. It's like a dream where characters do what they want and can move as they like. To conclude, six-year old children could have problems in decoding some symbols in textbook Magic Adventure 2. The problems could occur in: decoding "motion devices" and lack of material with which children could identify.

\subsection{Semiotic Analysis of the Textbook Playway to English 1}

In the textbook Playway to English 1 there are many symbols that require extra explanation from the teacher. The same symbols are repeated constantly throughout the textbook.

We will present them as symbols for moving, symbols for singing, symbol for thinking and symbols for jumping.

Motion is represented by the curved lines that surround Figure 4. What is more, the girl's body is reproduced several times. A six-year old child might decode this picture as meaning that there are several girls jumping in one in front of the other. On the other hand these curved lines could be interpreted as waves in the water or 


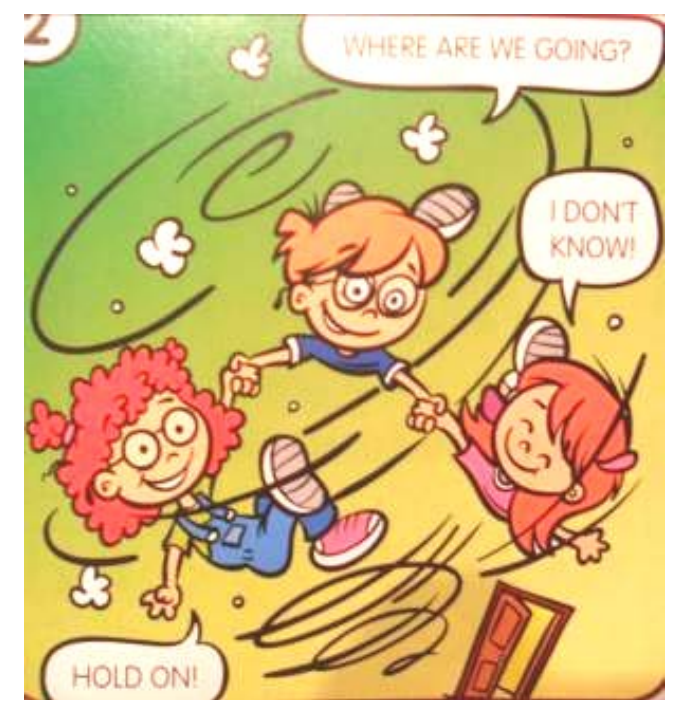

Figure 2. Flying. Source: Mol, 2011.

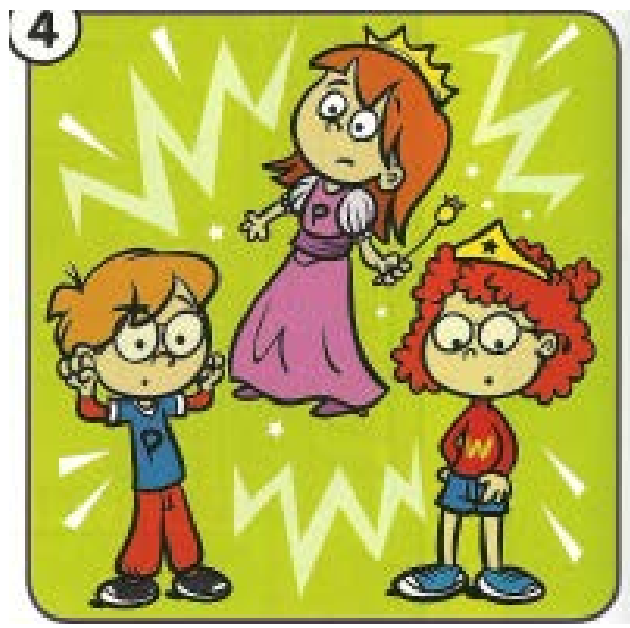

Figure 3. Shine. Source: Mol, 2011.

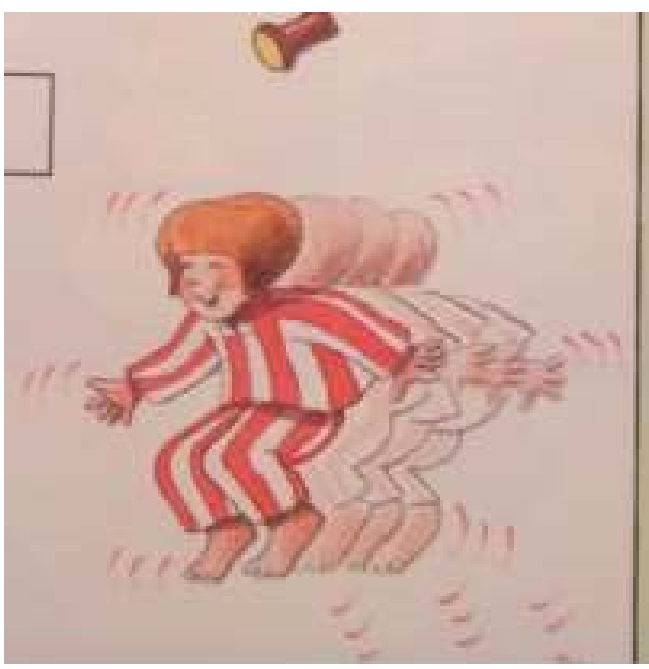

Figure 4. Moving. Source: Gerngross, 1998. 
something similar. What might also disrupt children's perception is that she is moving through the air, without any floor present. A child needs to be focused, and according to Karlavaris (1987) he/she must find some familiar things in the illustration, but here the only thing that could be familiar to children is the girl's posture. The total number of illustrations in the textbook Playway to English 1 is 128. On forty-six of these illustrations motion is included; this means in $36 \%$ of all illustrations.

The symbols for jumping are a unique feature of this textbook. They are shown as clouds and dotted line on Figure 5.

This use of the same symbol for different purposes is not appropriate for six-year old children, because it would probably be confusing and won't provide motivation for learning.

\section{Discussion}

We have to realize that, besides teachers, teaching material plays a crucial role in early foreign language learning. Teaching material has to be suitable for 6-year-old children. By "suitable" is meant that such material must follow and encourage the child's cognitive development. Children at this age learn through illustration. Particularly when they are learning a foreign language, the illustrations become very important teaching material, and if child/learner can't interpret them, the illustrations become senseless to them, and what is more, they could even be disruptive to the learning process.

We focused on textbook illustrations, because there is no intention that 6-year-old children would learn how to write letters in the foreign language; they will do much of their learning through or with the help of illustrations. Illustrations should provide material with which they are familiar and can identify with.

Our findings were that the illustrations in all three textbooks (Magic adventure 2, Cookie and friends, Playway to English 1) have similar deficiencies according to semiotics in illustrations. We identified a lot of illustration that present motion; except in Playway to English 1, more than 50\% of the illustrations include a "motion device". Why is so much motion implied in illustrations for children? We can find a crucial answer in our brain functioning. On the other hand, it is a reasonable question what happens to a person's attention if he/she is surrounded by multiple illustrations where motion is implied, particularly if we consider that the observer is a six-year old child who is just learning how to keep focus. We have to be very careful when there are so many illustrations with implied motion in textbooks, because this can provide negative encouragement for children. Children might have less concentration, be less calm and less focused on their work.

Is it really good for children to look at illustrations with implied motion on almost every page? Decoding these symbols might cause young learners some problems according to Karlavaris (1983), but new theories have been proved such as that even blind people use and understand "motion devides". On the other hand we must realize that Kennedy (2009) did researches on adults.

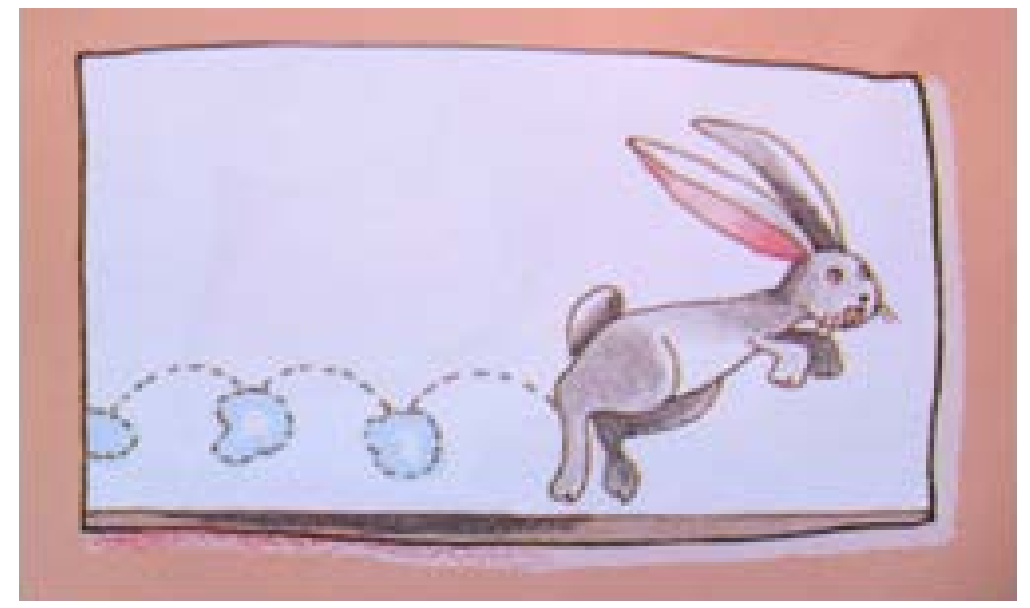

Figure 5. Rabbit. A six-year old child might think that the rabbit is peeing in clouds, or that he is breaking wind. A teacher will need to explain that these lines and clouds represent jumping. We want to stress that in this textbook the use of clouds is very frequent. Clouds are used as symbols for thinking, answering, jumping and car driving. Source: Gerngross, 1998. 
They used symbols that are hard for 6-year-old children to understand; furthermore, they also include letters and numbers in illustrations (except in Playway to English 1). Letters and numbers redirect the child's attention from the illustration to decoding letters or numbers. Furthermore a problem gets bigger if the illustration includes the shape of numbers and letters which aren't the same as the shape pupils have learned in Math or Slovene language. According to Yu (2007) this things could distract them. On the other hand problems could occur when the same symbols have different meaning. According to Karlavaris (1985) each symbol is learned and if pupils' don't get explanation about different meanings of symbols they will generalize the meaning or even connect symbols with wrong mean. On this point another question gets more attention. Do teachers realize that symbols are learned and that symbols need another explanation also as illustration?

We have to realize that on some points researchers do contradict each other, and today we are facing new facts about children's cognitive development and visual perception. Above all, to understand children's illustration means to get closer to what a child sees and that means to understand a child's brain functioning.

\section{Conclusions}

- A human-being is a creature who has a need to express itself through symbols. However if children can't decode the symbols, illustration becomes senseless for them.

- Decoding symbols is learned and needs special attention. Teachers and learning material play big role in helping pupils to recognize and decode symbols.

- "Motion devices" in illustrations cause more activity in our brain and consequently get more attention than illustrations with them. Textbook's illustration for young learners in textbooks Cookie and Friends, Magic Adventure 2 contain more than half illustrations with implied motion. In Playway to English 1 there are 36\% of illustrations with implied motion.

- In analyzed textbooks the same symbols are used for different meanings (in textbook Playway to English 1) one symbol presents three different concepts.

- Letters and numbers present symbols in children's perception. Different shapes of letters and numbers might confuse child's perception. Even if pupils at age 5 - 6 do know how to read sentences and numbers, it would probably be impossible for them to do so in the textbook Cookie and Friends.

\section{References}

Bregant, T. (2013). Learning and Brain Development. Sirikt 2013, Lecture Conducted from Ministry of Education and Sport, Kranjska Gora.

Clyde, J. (2003). Stepping Inside the Story World: The Subtext Strategy—A Tool for Connecting and Comprehending. The Reading Teacher, 57, 150-160.

Gerngross, G., \& Puchta, H. (1998). Playway to English 1. Cambridge: Cambridge University.

Harper, K., Reily, V., \& Covill, C. (2006). Cookie and Friends Starter. Oxford: University Press.

Kompare, A., Stražišar, M., \& Vec, T. (2001). Psihology-Illumination and Dilemma. Ljubljana DZS.

Kourtzi, Z., \& Kanwisher, N. (2000). Activation in Human Mt/mst by Static Images with Implied Motion. Journal of Cognitive Neuroscience, 12, 48-55. http://dx.doi.org/10.1162/08989290051137594

Kourtzi, Z., \& Nakayama, K. (2002). Distinct Mechanisms for the Representation of Moving and Static Objects. Visual Cognition, 9, 248-264. http://dx.doi.org/10.1080/13506280143000421

Mol, H., \& Joseph, N. (2011). Magic Adventure 2. Study Book for Early Learning of English Language. Ljubljana: Rokus Klett.

Šuštaršič, N., Butina, M., Zornik, K., Gleria, B., \& Skubin, I. (2004). Likovna Teorija Učbenikza Umetniške Gimnazije Likovna Smerod 1. do 4. letnika. Ljubljana: Debora.

Türkcan, B. (2013). Semiotic Approach to the Analysis of Children’s Drawings. Educational Sciences: Theory and Practice, 13, 600-607.

Yu, X. Y. (2007). Visual Perception in Relation to Levels of Meaning for Children. Doctor Dissertation, Texas: University of North Texas. 